\title{
A computational method to optimize energy savings of tension structures set in road tunnels
}

\author{
L.M. Gil-Martín ${ }^{1}$, A. Peña-García ${ }^{2}$, R. Escribano ${ }^{3}$ and A. Espín-Estrella ${ }^{2}$ \\ ${ }^{1}$ Department of Structural Mechanics. \\ ETSICCP, University of Granada. \\ Campus Fuentenueva - 18071 Granada (Spain) \\ Phone number: +34 958249 962, e-mail: $\underline{\text { mlgil @ugr.es }}$ \\ ${ }^{2}$ Department of Civil Engineering. \\ ETSICCP, University of Granada. \\ Campus Fuentenueva - 18071 Granada (Spain) \\ Phone number: +34 958249 435, e-mail: pgarcia@ugr.es, aespin@ugr.es \\ ${ }^{3}$ Department of Graphical Expression in Architecture and Engineering. \\ ETSIE, University of Granada. \\ Campus Fuentenueva - 18071 Granada (Spain) \\ Phone number: +34 958243 115, e-mail: rogaes@ugr.es
}

E-mail to: pgarcia@ugr.es

\begin{abstract}
After the successful introduction of transparent tension structures in the portal of road tunnels as an effective measure for energy savings, optimization of such savings has been sought. A computational method based on graphical design capable to simulate the optical properties of the sun, any transparent tension structure and any road tunnel whatever its orientation, has been developed and presented in this paper. A comparison with measurements in a real tension structure placed in the entrance portal of one real tunnel is performed and discussed.
\end{abstract}

\section{Keywords}

Energy Saving, Solar Radiation, Graphical Design, Electrical Lighting, Road Safety.

\section{Introduction}

Road tunnel lighting is one of the most complex problems when dealing with electrical lighting $[1,2]$. Furthermore, in addition to the difficulty of implementing accurate solutions to ensure the correct visibility inside road tunnels (which is a really hard task due to the high variability between the visual systems of drivers), we find that the energetic requirements of tunnel lighting are extremely high because it is necessary that the driver visual system does not suffer any important change in levels of illuminance when going into these structures.

In previous works [3, 4], we demonstrated that implementation of transparent tension structures in the portal of road tunnels could be a very effective an easy measure to use the sunlight during daytime, which is the most critical period of the day when dealing with tunnel lighting. Nevertheless, the advances above were carried out with very simple tension structures because the target was to prove whether they were reliable and profitable.

Furthermore, any test to prove the effectiveness of these structures or look for optimal ones, should be carried out in real tunnels, which, besides the risks for safety, required huge investments in money, human efforts and legal bureaucracy.

Hence, the search of an effective tool to optimize the structures and energy savings in each different condition without going to tests in real tunnels became the main objective of this line of research. One tool that can determine which tension structure is better for each tunnel, will allow us to set such structures in every tunnel with the most optimal compromise 
between energy saving, levels of lighting and mechanical properties of the structure itself.

In order to achieve this target, it is necessary to remark that the optimal lighting system for one given tunnel, depends on its relative orientation because the position of the sun with regard to the driver's eye will determine how much light is necessary [5]. This means that the tension structure for each tunnel would need a specific test, which is clearly unrealizable.

The tool found is a computational method to simulate both tunnel and structure with no waste of construction materials nor expensive and dangerous tests.

Hence, the main objective of this work is to present a method to find the most optimal transparent tension structure that can be set on the portal of each tunnel with the highest energy savings.

Given the high complexity of modelling the photometric properties of sun, structures and tunnels, one critical objective of this work is to present an effective way to calibrate the software with real parameters of the elements to simulate.

Besides the interesting applications in matter of visual performance and Civil Engineering, the success of this method will guarantee the achievement of some targets that are also objectives of this work:

- Energy saving.

- Saving in the number of luminaries and lamps with the consequent reduction on the environmental impact (industrial waste, $\mathrm{CO}_{2}$ emissions, recycling ...).

- Saving in building materials through the implementation of tension structures.

\section{Materials and Method}

In order to optimize the transparent tension structure necessary for each road tunnel, we have modelled the sun (with its relevant trajectory in a given day in any location in the world), the tunnel under consideration and the candidate tension structures with free software (Blender). Figure 1 shows the modelled sun trajectory for an arbitrary tunnel.

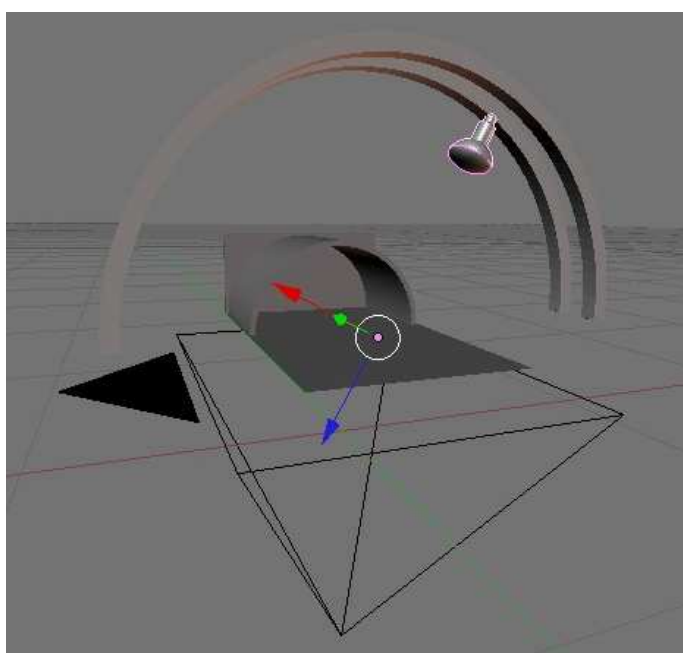

Fig. 1. Computational modelling of tunnel, sun and sun ecliptic.

The modelled tunnel and the tension structure have been the same used for real measurements in previous works $[3,4]$. The tunnel is located in Granada. This city is in Andalusia, in the Southern of Spain, where luminosity is very high for the most part of the year.

It is an underpass of a highway with an axis heading of $73^{\circ}$ and an oval section comprising three arcs of ellipse. It is shown in figure 2 below.

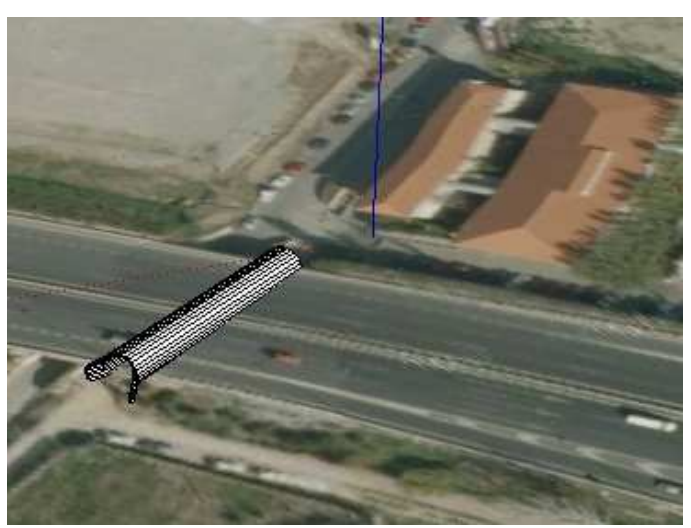

Fig. 2. Satellite view of the modelled tunnel (Google Earth).

Finally, we have simulated the tension structure in the gate of the road tunnel. As mentioned, it is also the same we used for the measurements in $[3,4]$. The simulation is shown in figure 3 . 


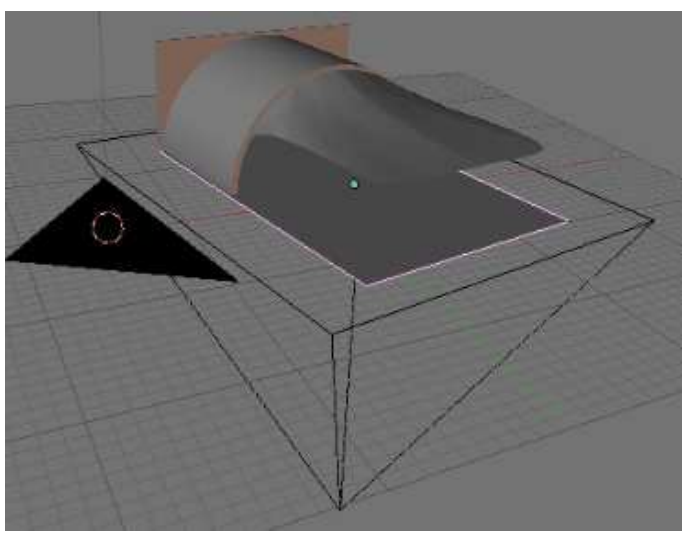

Fig. 3. Computational modelling of tunnel and simple tension structure.

\section{Results}

First of all, it has been necessary to calibrate the tool. Such calibration has been carried out by comparing the illuminance values measured in a scaled mock-up simulating one generic road tunnel and the output of the software when simulating sun and tunnel gate also. The correspondence between software output and illuminance measures, that is, the calibration coefficient finally results to be $\mathrm{C}=1.15563$.

This shows that the first values yielded by the software fit the real values measured in a mockup in a very accurate way. Nevertheless, although very near to 1 , the calibration coefficient will be introduced in the output of the program.

The values yielded from the simulated sun under these structures are shown in Table I.

\begin{tabular}{||c|c|c|c||}
\hline \hline \multirow{2}{*}{$\begin{array}{c}\text { Distance } \\
\text { portal }(\mathrm{m})\end{array}$} & \multicolumn{3}{|c||}{ Illuminance (lux) } \\
\cline { 2 - 4 } & Left & Central & Right \\
\hline 0 & 1616 & 1569 & 1703 \\
\hline 1 & 2459 & 2267 & 2487 \\
\hline 2 & 3229 & 2926 & 3308 \\
\hline 3 & 3797 & 3488 & 3906 \\
\hline 4 & 4283 & 4075 & 4439 \\
\hline 5 & 4855 & 4644 & 4992 \\
\hline 6 & 14481 & 14382 & 14757 \\
\hline 7 & 15252 & 15254 & 15608 \\
\hline
\end{tabular}

Table I. Simulated illuminance (lux) in each side of the road under the structure. Distances in $\mathrm{m}$.

These values, yielding a mean illuminance $E_{m}=6241$ lux, accurately agree with the results obtained in real situations. Even considering that the real tunnel is located in a very inhomogeneous and unusual environment (it is the very frontier between the town and its outskirts), which is almost impossible to model, these values prove that the computational method developed is reliable.

The simulated situation can be graphically observed in the screen caption below (Fig. 4), which shows the light-shadow distribution on the ground for the simulated situation.

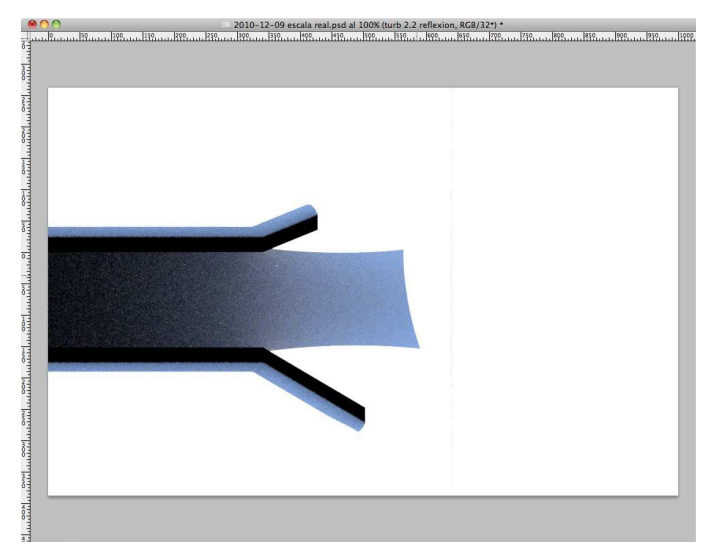

Fig. 4. Light distribution below the tension structure for the simulated situation.

Concerning the relationship between the illuminance requested in the relevant regulation and the one yielded by the simulation, Table II below shows the values of mean illuminance in the threshold zone of the road tunnel under study. This illuminance, which can be easily calculated with the $\mathrm{L}_{20}$ method $[5,6]$, depends on the maximum speed allowed inside the tunnel. For the typical maximum speeds of 80 and $100 \mathrm{~km} / \mathrm{h}$, the necessary illuminances would be mostly yielded by the tension structure as shown in the table:

\begin{tabular}{||c|c|c||}
\hline $\begin{array}{c}\text { MAXIMUM } \\
\text { SPEED } \\
(\mathrm{KM} / \mathrm{H})\end{array}$ & $\begin{array}{c}\text { NECESSARY } \\
\mathrm{E}_{\mathrm{M}} \text { (LUX) }\end{array}$ & $\begin{array}{c}\text { SIMULATED } \\
\mathrm{E}_{\mathrm{M}} \text { (LUX) }\end{array}$ \\
\hline 80 & 7890 & 6241 \\
\hline 100 & 10995 & 6241 \\
\hline
\end{tabular}

Table II. Comparison between required and simulated illuminances (lux).

Hence, the energy savings according to the carried simulation can be summarized in Table III below where it is evident that the lower the maximum speed, the higher the energy saving. This situation is due to the direct influence of 
the maximum speed in the length of the threshold zone [5].

\begin{tabular}{||c|c||}
\hline $\begin{array}{c}\text { MAXIMUM SPEED } \\
(\mathrm{KM} / \mathrm{H})\end{array}$ & $\begin{array}{c}\text { ENERGY } \\
\text { SAVING }(\%)\end{array}$ \\
\hline 80 & 79 \\
\hline 100 & 57 \\
\hline
\end{tabular}

Table III. Energy savings for two typical maximum speeds in road tunnels

The results above show the reliability of the developed method. They can be even improved with finer parameterization of the tunnel surrounding but, the complexity of the study case, which was half urban and half rural, has made better to underestimate the results instead of taking some kind of risked assumptions.

In typical road tunnels, surrounded by mountains, sky, road and bushes, the parameterization of the surroundings will be immediate and $100 \%$ reliable.

\section{Conclusions}

We have developed a reliable computational method to simulate the optical properties of tension structures when set in the portal of tunnels to use sunlight. The position and radiative properties of the sun are also simulated with this method. It means that the method is valid whatever the orientation of one given tunnel, which is the most critical parameter in the design of its electrical lighting. The results obtained in each case allow to easily decide the best tension structure to save energy due to electrical lighting in each road tunnel without expensive and time costing tests.

\section{Acknowledgement}

This research work was carried out under the financial support provided by Spanish Ministry of Education and Science as part of the Research Projects BIA 2007-62595.

\section{References}

[1] W. Adrian, "Investigations on the required luminance in tunnel entrances", Lighting Res. Technol. Vol. 14, pp. 151-159, 1982.

[2] D. A. Schreuder, "Tunnel entrance lighting: a comparison of recommended practice", Lighting Res. Technol. Vol. 3, pp. 274-278, 1971.

[3] L.M. Gil-Martín, A. Peña-García, E. Hernández-Montes, A. Espín Estrella, "Tension structures: A way towards sustainable lighting in road tunnels", Tunnelling and Underground Space Technology, Vol. 26, pp. 223-227, 2011.

[4] A. Peña García, L.M. Gil Martín, A. Espín Estrella, F. Aznar Dols, "Energy saving in road tunnels by means of transparent tension structures". International Conference on Renewable Energies and Power Quality (ICREPQ'10). Granada (Spain), 2010. ISBN: 978-84-613-7543-1.

[5] Commission International de l'Éclairage (CIE), "Guide for the lighting of road tunnels and underpasses", CIE Publ. 88, $2^{\text {nd }}$ Ed, Vienna, 2004.

[6] P. Blaser and H. Dudli, "Tunnel lighting: Method of calculating luminance of access zone $\mathrm{L}_{20}$ ", Lighting Res. Technol., Vol. 25, pp. 25-30, 1993. 